\title{
Preventing vitamin D deficiency during the COVID-19 pandemic: UK definitions of vitamin D sufficiency and recommended supplement dose are set too low 临
}

\author{
Authors: George Griffin, ${ }^{\mathrm{A}}$ Martin Hewison, ${ }^{\mathrm{B}}$ Julian Hopkin, ${ }^{\mathrm{C}}$ Rose Anne Kenny, ${ }^{\mathrm{D}}$ Richard Quinton, ${ }^{\mathrm{E}}$ Jonathan Rhodes ${ }^{\mathrm{F}}$ \\ Sreedhar Subramanian ${ }^{G}$ and David Thickett ${ }^{H}$
}

\begin{abstract}
There is growing evidence linking vitamin D deficiency with risk of COVID-19. It is therefore distressing that there is major disagreement about the optimal serum level for 25-hydroxyvitamin D (25(OH)D) and appropriate supplement dose. The UK Scientific Advisory Committee for Nutrition has set the lowest level for defining sufficiency $(10 \mathrm{ng} / \mathrm{ml}$ or $25 \mathrm{nmol} / \mathrm{L}$ ) of any national advisory body or scientific society and consequently recommends supplementation with 10 micrograms (400 IU) per day. We have searched for published evidence to support this but not found it. There is considerable evidence to support the higher level for sufficiency $(20 \mathrm{ng} / \mathrm{ml}$ or $50 \mathrm{nmol} / \mathrm{L}$ ) recommended by the European Food Safety Authority and the American Institute of Medicine and hence greater supplementation (20 micrograms or 800 IU per day). Serum 25(OH)D concentrations in the UK typically fall by around $50 \%$ through winter. We believe that governments should urgently recommend supplementation with 20-25 micrograms (800-1,000 IU) per day.
\end{abstract}

KEYWORDS: vitamin D, COVID-19, guidelines

DOI: $10.7861 /$ clinmed.2020-0858

\section{Vitamin D, COVID-19 and current guidance}

Evidence for a possible impact of vitamin D deficiency on COVID-19 has been strengthened recently by the positive Spanish trial of 25-hydroxyvitamin D3 (25(OH)D3 or calcifediol) in hospitalised

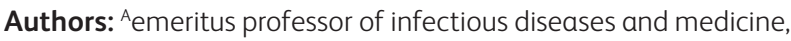
St George's, University of London, London, UK; B professor of molecular endocrinology, University of Birmingham, Birmingham,

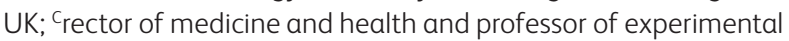
medicine, Swansea University, Swansea, UK; Dprofessor of medical gerontology, Trinity College Dublin, Dublin, Ireland; Esenior lecturer in endocrinology, Newcastle University, Newcastle upon Tyne, UK; Femeritus professor of medicine, University of Liverpool, Liverpool, UK; ${ }^{G}$ Consultant gastroenterologist, Royal Liverpool University Hospital, Liverpool, UK; ${ }^{H}$ professor in respiratory medicine, University of Birmingham, Birmingham, UK patients ${ }^{1}$ and by the association between vitamin $D$ deficiency and increased risk for COVID-19 seropositivity found in hospital staff from Birmingham, UK. ${ }^{2}$ There is a plausible scientific basis for this as $25(\mathrm{OH}) \mathrm{D} 3$ is a prohormone that can be metabolised to active, hormonal 1,25-dihydroxyvitamin D3 (1,25(OH)2D3). When bound to its intracellular vitamin D receptor (VDR), 1,25(OH)2D3 is able to regulate many target genes, with beneficial effects on immune and lung cell function that may be compromised by vitamin D deficiency. ${ }^{3}$ In the UK, serum $25(\mathrm{OH}) \mathrm{D}$ concentrations fall by about $50 \%$ from a peak in September to a trough in February (Fig 1). ${ }^{4}$ With much of the northern hemisphere experiencing a resurgence of the pandemic as we move into winter, it is increasingly urgent to ensure appropriate public health measures to prevent vitamin D deficiency.

There is unfortunately considerable variance between countries in recommendations for supplementation: 10 micrograms (400 IU) per day in the UK, 600 IU per day in the EU and 600 IU per day or 800 IU per day for those aged $>70$ years in the USA. ${ }^{5}$ The UK Scientific Advisory Committee on Nutrition (SACN) is an outlier among representative bodies in choosing the lowest blood level $(25 \mathrm{nmol} / \mathrm{L})$ of $25(\mathrm{OH}) \mathrm{D}$ to define sufficiency when compared with thresholds of $50 \mathrm{nmol} / / \mathrm{l}$ set by the American Institute of Medicine (now National Academy of Medicine) and European Food Safety Authority, and $75 \mathrm{nmol} / / \mathrm{l}$ set by the US Endocrine Society. The evidence base underlying the UK target serum level has been questioned by others, ${ }^{6}$ and we now explore it further.

Seeking the evidence base for the UK SACN threshold for vitamin D sufficiency at $25 \mathrm{nmol} / \mathrm{L}$

SACN in their 2016 report $^{7}$ state ( $p 43$, section 6.17): 'In the UK, a serum $25(\mathrm{OH}) \mathrm{D}$ concentration $<25 \mathrm{nmol} / \mathrm{L}$ has been the threshold adopted to define increased risk of rickets ( $\mathrm{DH}, 1998)$.'

In turn, the $\mathrm{DH}$ (Department of Health) 1998 report $^{8}$ states (p40 6.2.3):

Plasma levels of $25(\mathrm{OH})$ vitamin D found in clinical rickets or osteomalacia range from undetectable to around 20nmo1/l [citing the $1991 \mathrm{DH}$ report of the Panel on Dietary Reference Values of the Committee on Medical Aspects of Food Policy ${ }^{9}$ ] and a level of plasma $25(\mathrm{OH})$ vitamin D of $25 \mathrm{nmo1/l}$ has conventionally been used as a cut off for defining the lower limit of adequacy of vitamin D status [citing Grindulis et al $1986^{10}$ ], although others have suggested slightly higher levels [citing Gloth et al 1995'11]. 


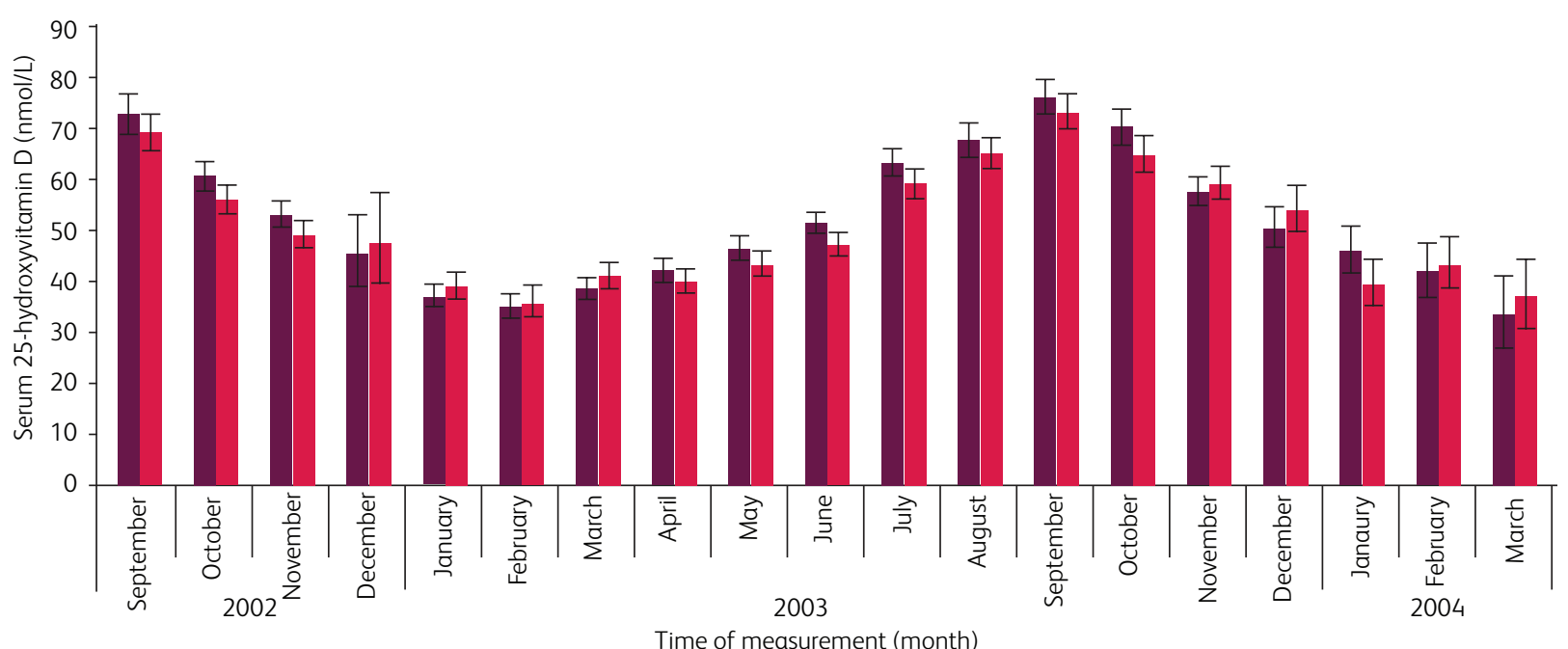

Time of measurement (month)

Fig 1. Seasonal variation in serum vitamin D concentrations (mean (95\% confidence interval)) among 7,437 white British (1958 British birth cohort) at age 45. Dark red bar $=$ male, red bar $=$ female. Adapted with permission from Hypponen and Power 2007. ${ }^{4}$

The $\mathrm{DH}$ reports ${ }^{8,9}$ that underpin the SACN position do not stand close scrutiny. The $1991 \mathrm{DH}$ report ${ }^{9}$ states (section 18.1.2): 'Plasma 25(OH)D concentrations in rickets range from not detectable to about $8 \mathrm{ng} / \mathrm{ml}$ ', citing Arnaud et al. ${ }^{12}$ However, this is definitely not what Arnaud et al reported: a case series of nine children with nutritional rickets, seven of whom had serum $25(\mathrm{OH}) \mathrm{D}$ concentrations above $10 \mathrm{ng} / \mathrm{ml}(=25 \mathrm{nmol} / \mathrm{L})$ and up to approximately $50 \mathrm{nmol} / \mathrm{L}$.

Grindulis et $a{ }^{10}$ did indeed state: 'For this study a vitamin D concentration $<10 \mathrm{ng} / \mathrm{ml}(25 \mathrm{nmol} / \mathrm{L}$ ) was taken to be suboptimal and $<5 \mathrm{ng} / \mathrm{ml}$ deficient' but no data were referenced in support of this statement.

Gloth et al11 state: 'Reference ranges for our laboratory (normal range), 25 to $137 \mathrm{nmol} / \mathrm{L}$ ( 10 to $55 \mathrm{ng} / \mathrm{mL}$ )'. In the discussion of this paper, however they question the validity of the lower limit, commenting that:

the elevation in intact PTH levels seen with 25-OHD serum levels between 25 and $37 \mathrm{nmol} / \mathrm{L}$ (10 and $15 \mathrm{ng} / \mathrm{mL}$ ) is distressing if we define a vitamin deficiency as the Food and Nutrition Board does, ie, 'that level of an essential nutrient that leads to an abnormal physiologic change.' Since secondary hyperparathyroidism causes abnormal bone loss, among other physiological changes, then perhaps the lower limit of the normal range for serum 25-OHD should be increased.

Here the trail 'runs dry' - seemingly the $25 \mathrm{nmol} / \mathrm{L}$ limit has been agreed by consensus within SACN rather than by referral to any specific source with the possible exception of the historic laboratory reference range ( 25 to $137 \mathrm{nmol} / \mathrm{L}$ ) of the Johns Hopkins University School of Medicine, Baltimore as cited, but criticised, in Gloth et al.11

It is interesting that the earlier SACN (2007) position statement was much more circumspect and concluded ( $p 38$, section 13.118):

Accumulating evidence suggests that vitamin D may be important for health outcomes other than rickets and osteomalacia, and that plasma concentrations of $25(\mathrm{OH}) \mathrm{D}$ several fold higher than $25 \mathrm{nmol} / \mathrm{L}$ may be required for optimal health.

It is unclear why subsequent SACN reports have not addressed this.

It seems then that the UK SACN definition of vitamin D deficiency as $<25 \mathrm{nmol} / \mathrm{L}$ and consequently the $400 \mathrm{IU}$ per day supplement dosing was based on consensus rather than on any systematic analysis of data. It may be more than a coincidence that 400 IU is approximately the amount of vitamin D in one teaspoon of cod liver oil, for over 70 years the standard daily supplement recommended in Norway. With the passage of time and subsequent reports from SACN this position seems to have become firmly entrenched without any further evidence to justify it.

The SACN/UK government advised dietary intake level of $400 \mathrm{IU}$ per day for all $>4$ years was re-affirmed in June $2020^{13}$ on the account that:

This is the average daily amount of vitamin D (from natural food sources, fortified foods or supplements) needed by the majority (97.5\%) of the population to maintain a serum $25(\mathrm{OH})$ $D$ concentration $\geq 25 \mathrm{nmol} / \mathrm{L}$ when UVB sunshine exposure is minimal.

The ' $97.5 \%$ ' is presumably based on the definition of reference nutrient intake (RNI) as used by DH (1998) - 'two standard deviations above estimated average requirements'. In 1998 the Department of Health set no RNI for older children or for adults aged $18-64$ but did set 400 IU (10 microgram) per day as the recommendation for adults $\geq 65 .{ }^{8}$ This report cited a randomised trial comparing no supplement with 400 IU per day and 800 IU per day completed through to 1 year in 109 institutionalised elderly people. This showed that serum $25(\mathrm{OH}) \mathrm{D}$ increased to $>40 \mathrm{nmol} / \mathrm{L}$ in all subjects who received either $400 \mathrm{IU}$ or $800 \mathrm{IU}$ per day. ${ }^{14}$ This does not however address the greatly increased vitamin D supplement requirements needed to achieve sufficiency in people with obesity. ${ }^{15}$ 


\section{The evidence base for $50 \mathrm{nmol} / \mathrm{L}$ as the threshold for 25(OH)D sufficiency}

This has been reviewed elsewhere. ${ }^{5}$ The American Institute of Medicine (now called the National Academy of Medicine) and the European Food Safety Authority both set $>50 \mathrm{nmol} / \mathrm{L} 25(\mathrm{OH}) \mathrm{D}$ as the definition for sufficiency while the US Endocrine Society sets a higher level of $>75 \mathrm{nmol} / \mathrm{L}$. Serum concentrations of parathyroid hormone rise with vitamin $\mathrm{D}$ deficiency but there is considerable variation between individuals. Evidence supporting $50 \mathrm{nmol} / \mathrm{L}$ as a recommended serum vitamin $25(\mathrm{OH}) \mathrm{D}$ level was strengthened by Malabanan et $a{ }^{16}$ who looked at the impact of vitamin $D$ supplementation on parathyroid hormone levels in 35 people with different baseline levels of 25(OH)D. People with baseline serum $25(\mathrm{OH}) \mathrm{D}$ concentrations in the ranges $27.5-39.9$ and $40-49.9$ $\mathrm{nmol} / \mathrm{l}$ showed significant falls in parathyroid hormone in response to vitamin D supplementation whereas people with baseline $25(\mathrm{OH}) \mathrm{D} \geq 50 \mathrm{nmol} / / \mathrm{l}$ showed no significant fall in parathyroid hormone.

Muscle strength has also been studied as an outcome measure to define vitamin D sufficiency. Interestingly, the SACN (2016) report says ( $p 68$, section 6.169):

\section{Evidence from cohort studies was also supportive of an} association between mean serum 25(OH)D concentration and muscle strength and function when baseline serum $25(\mathrm{OH}) \mathrm{D}$ concentration is $<50 \mathrm{nmol} / \mathrm{L}$.

Other studies have looked more broadly at associations between vitamin D status and all-cause mortality. Gaksch and colleagues ${ }^{17}$ performed a meta-analysis across a European consortium of eight prospective studies including 26,916 study participants, median age 61.6 years, followed-up for median 10.5 years.

Significant increases in all-cause mortality were seen with baseline serum $25(\mathrm{OH}) \mathrm{D}<50 \mathrm{nmol} / \mathrm{L}$. There was no significant increased mortality risk at high levels up to $125 \mathrm{nmol} / \mathrm{L}$, important since an earlier study had suggested a possible U-shaped dose response curve. ${ }^{18}$

There is therefore a substantial body of evidence to support the $50 \mathrm{nmol} / \mathrm{L}$ definition of $25(\mathrm{OH}) \mathrm{D}$ sufficiency as set by the American Institute of Medicine and the European Food Safety Authority.

In the UK $55.4 \%$ of the population, rising to $69.3 \%$ in winter, are reported to have serum $25(\mathrm{OH}) \mathrm{D}<50 \mathrm{nmol} / \mathrm{L}$ and black,
Asian, and minority ethnic populations, as well as people who by occupation or institutionalisation receive less sunlight exposure, are at still higher risk of insufficiency. ${ }^{19} \mathrm{~A}$ recent study of the UK Biobank cohort found that $92 \%$ of 6,433 UK-dwelling South Asians have $25(\mathrm{OH}) \mathrm{D}<50 \mathrm{nmol} / \mathrm{L} .{ }^{20}$

\section{Identification of the daily supplement dosage needed to achieve optimal vitamin $D$ status defined as $\geq 50 \mathrm{nmol} / \mathrm{L}$}

Modelling based on a meta-analysis of 94 cohort studies that included 11,566 individuals supplemented for a median period of 274 days suggests that for adults, supplementation with 800 IU per day (but not 400 IU per day) should be adequate, even in obese individuals, for achieving $>50 \mathrm{nmol} / \mathrm{L}$ (Table 1). ${ }^{21}$ However, to achieve $>75 \mathrm{nmol} / \mathrm{L}$ would typically require supplementation of between 3,000 IU per day to 4,000 IU per day for an obese individual. It seems reasonable to conclude from this metaanalysis that a regular daily intake of at least 800 IU should be sufficient, even in obese individuals, to achieve a target blood level $>50 \mathrm{nmol} / \mathrm{L}$. A higher initial daily intake, eg 4,000 IU per day for the first 4 weeks, would be reasonable to achieve sufficiency quickly in people likely to be deficient during the current pandemic. Intermittent blood 25(OH)D monitoring and personalised replacement, although scientifically ideal, has a cost and is not essential given the safety of vitamin $D$ supplementation at appropriate dosage.

Regarding safety, SACN (2016) concludes that:

Upper limits for vitamin D recommended by EFSA, of $100 \mu \mathrm{g} / \mathrm{d}$ (4000 IU/d) for adults and children aged 11-17 y, $50 \mu \mathrm{g} / \mathrm{d}$ (2000 IU/d) for children aged 1-10 y, and $25 \mu \mathrm{g} / \mathrm{d}$ (1000 IU) for infants, are considered appropriate. The upper limits do not distinguish between total and supplementary vitamin D intake since dietary intakes of vitamin D make only a small contribution to total exposures at the ULs. ${ }^{?}$

\section{Conclusion}

The current UK SACN threshold for vitamin D sufficiency of $25 \mathrm{nmol} / \mathrm{L} 25(\mathrm{OH}) \mathrm{D}$ is set too low and is not supported by evidence. A higher threshold of $50 \mathrm{nmol} / \mathrm{L}$ is supported by the evidence and is safely achievable by supplementation with at least 800 IU per day

Table 1. Calculated daily vitamin D3 dose for achieving in vitamin D-deficient individuals target 25-hydroxyvitamin $D$ levels of $50 \mathrm{nmol} / \mathrm{L}$ and $75 \mathrm{nmol} / \mathrm{L}$, respectively

\section{0-year-old person}

Target 25(OH)D level $50 \mathrm{nmol} / \mathrm{L}$

$50 \mathrm{~kg}$ body weight

$75 \mathrm{~kg}$ body weight

$100 \mathrm{~kg}$ body weight

Target 25(OH)D level $75 \mathrm{nmol} / \mathrm{L}$

$50 \mathrm{~kg}$ body weight

$75 \mathrm{~kg}$ body weight

$100 \mathrm{~kg}$ body weight
9 micrograms (360 IU)

13.5 micrograms (540 IU)

18 micrograms (720 IU)

42 micrograms (1680 IU)
63 micrograms (2520 IU)
84 micrograms (3360 IU)
24 micrograms (960 IU)

36.5 micrograms (1460 IU)

49 micrograms (1960 IU) 70-year-old person

5 micrograms (200 IU)

7.7 micrograms (308 IU)

10 micrograms (400 IU)

Based on a systematic review of 94 cohort studies that included 11,566 supplemented individuals (Zittermann et a ${ }^{21}$ ). Baseline 25(OH)D level $25 \mathrm{nmol} / \mathrm{L}$ 
(20 micrograms per day). Since vitamin $D$ is widely sold in 1,000 IU capsules, and it is universally agreed that doses up to 4,000 IU per day are safe, then a recommendation of 800-1,000 IU per day (20-25 micrograms per day) for all adults would be safe and sufficient and should be urgently promoted.

\section{Conflicts of interest}

Martin Hewison and David Thickett have received speaking honoraria from Thornton Ross.

\section{References}

1 Castillo ME, Entrenas Costa LM, Vaquero Barrios JM et al. Effect of calcifediol treatment and best available therapy versus best available therapy on intensive care unit admission and mortality among patients hospitalized for COVID-19: A pilot randomized clinical study. J Steroid Biochem Mol Biol 2020;203:105751.

2 Faniyi AA, Lugg ST, Faustini SE et al. Vitamin D status and seroconversion for COVID-19 in UK healthcare workers who isolated for COVID-19 like symptoms during the 2020 pandemic. medRxiv 2020.10.05.20206706

3 Rhodes JM, Subramanian S, Laird E et al. Perspective: Vitamin D deficiency and COVID-19 severity - plausibly linked by latitude, ethnicity, impacts on cytokines, ACE2 and thrombosis. J Intern Med 2020, in press (doi: 10.1111/joim.13149).

4 Hypponen E, Power C. Hypovitaminosis D in British adults at age $45 y$ : nationwide cohort study of dietary and lifestyle predictors. Am J Clin Nutr 2007:85:860-8.

5 Bouillon R. Comparative analysis of nutritional guidelines for vitamin D. Nat Rev Endocrinol 2017;13:466-79.

6 Giustina A, Adler RA, Binkley N et al. Consensus statement from 2nd International Conference on Controversies in Vitamin D. Rev Endocr Metab Disord 2020;21:89-116.

7 Scientific Advisory Committee on Nutrition. Vitamin D and Health. SACN, 2016. https://assets.publishing.service.gov.uk/government/ uploads/system/uploads/attachment_data/file/537616/SACN_ Vitamin_D_and_Health_report.pdf.

8 Department of Health. Nutrition and Bone health: with particular reference to calcium and vitamin D. Report on the Subgroup on Bone Health, Working Group on the Nutritional Status of the Population of the Committee on Medical Aspects of Food and Nutrition Policy. London, The Stationery Office, 1998.

9 Department of Health. Dietary reference values for food energy and nutrients for the United Kingdom. London, The Stationery Office, 1991.
10 Grindulis H, Scott PH, Bolton NR, Wharton BA. Combined efficiency of iron and vitamin D in Asian toddlers. Arch Dis Child 1986; 61:843-8.

11 Gloth FM III, Grundberg CM, Hollis BW, Haddad JG, Tobin JD. Vitamin D deficiency in homebound elderly persons. JAMA 1995; 274:1683-6.

12 Arnaud SB, Stickler GB, Haworth JC. Serum 25-hydroxyvitamin D in infantile rickets. Pediatrics 1976;57:221-5.

13 Scientific Advisory Committee on Nutrition. Rapid review: Vitamin $D$ and acute respiratory tract infections. SACN, 2020. https://app. box.com/s/g0ldpth1upfd7fw763ew3aqa3c0pyvky.

14 Lips P, Wiersinga A, van Ginkel FC et al. The effect of vitamin D supplementation on vitamin D status and parathyroid function in elderly subjects. J Clin Endocrinol Metab 1988;67:644-50.

15 Bassatne A, Chakhtoura M, Saad R, Fuleihan GE. Vitamin D supplementation in obesity and during weight loss: A review of randomized controlled trials. Metabolism 2019;92:193-205.

16 Malabanan A, Veronikis IE, Holick MF. Redefining vitamin D insufficiency. Lancet 1998;351:805-6.

17 Gaksch M, Jorde R, Grimnes G et al. Vitamin D and mortality: Individual participant data meta-analysis of standardized 25-hydroxyvitamin D in 26916 individuals from a European consortium. PLOS ONE 2017;12:e0170791.

18 Amrein K, Quraishi SA, Litonjua AA et al. Evidence for a U-shaped relationship between prehospital vitamin D status and mortality: a cohort study. J Clin Endocrinol Metab 2014;99:1461-9.

19 Cashman KD, Dowling KG, Škrabáková Z et al. Vitamin D deficiency in Europe: pandemic? Am J Clin Nutr 2016;103:1033-44.

20 Darling AL, Blackbourn DJ, Ahmadi KR, Lanham-New SA. Very high prevalence of 25-hydroxyvitamin D deficiency in 6433 UK South Asian adults: analysis of the UK Biobank Cohort. Br ] Nutr 2020, in press (doi: 10.1017/S0007114520002779).

21 Zittermann A, Ernst JB, Gummert JF, Börgermann J. Vitamin D supplementation, body weight and human serum 25-hydroxyvitamin D response: a systematic review. Eur ] Nutr 2014;53:367-74.

Address for correspondence: Prof Jonathan Rhodes, Department of Cellular and Molecular Physiology, Institute of Translational Medicine, Henry Wellcome Laboratory, Nuffield Building, Crown Street, Liverpool L69 3GE, UK.

Email: rhodesjm@liverpool.ac.uk 